MEDIKA ALKHAIRAAT : JURNAL PENELITIAN KEDOKTERAN DAN KESEHATAN 1(2): $46-51$

e-ISSN: 2656-7822, p-ISSN: 2657-179X

\title{
DESKRIPSI PENGETAHUAN DAN SIKAP IBU HAMIL TRIMESTER III TENTANG SENAM HAMIL
}

\author{
Mudyawati Kamaruddin ${ }^{1, *}$, Sitti Usmia ${ }^{1}$ \\ ${ }^{1}$ Midwifery Academy, Tahirah Al Baeti, Bulukumba, South Sulawesi, Indonesia \\ *Corresponding author: Telp: +628111520603, email: mudya07@gmail.com
}

\begin{abstract}
ABSTRAK
Pada umumnya wanita yang sedang hamil takut menghadapi proses persalinan karena rasa sakit yang menimbulkan rasa takut dan cemas, hal ini dapat menimbulkan ketegangan fisik yang mengakibatkan kakunya otot-otot dan persendian yang tidak wajar sehingga perlu dilakukan senam hamil. Senam hamil merupakan salah satu latihan fisik berupa beberapa gerakan tertentu yang mendukung kemudahan dalam persalinan dan dilakukan khusus untuk meningkatkan kesehatan ibu hamil. Penelitian ini bertujuan untuk mengetahui gambaran pengetahuan dan sikap ibu hamil trimester III tentang senam hamil. Penelitian ini dilakukan pada 42 sampel ibu hamil trimester III di Puskesmas Tanete, Bulukumba dengan teknik sampling berupa accidental sampling yaitu pengambilan sampel didasarkan pada kenyataan bahwa responden kebetulan muncul. Pengumpulan data berupa kuesioner untuk mengetahui pengetahuan dan sikap responden tentang senam hamil dengan menganalisa tingkat pendidikan masing-masing responden. Hasil penelitian menunjukkan terdapat hubungan yang signifikan antara tingkat pendidikan dengan pengetahuan ibu hamil terhadap senam hamil dengan $p$ value $=0,00$. Sedangkan tingkat pendidikan dan sikap ibu hamil terhadap senam hamil tidak terdapat hubungan $p$ value sebesar 0,824 . Dari 45 ibu hamil yang diteliti yang mempunyai pengetahuan baik terhadap senam hamil sebesar 26,2\% yaitu dengan tingkat pendidikan sekolah menengah atas, walau pengetahuan senam hamil ini pula terdistribusi pada pengetahuan yang cukup yaitu sebesar $28,6 \%$ dengan tingkat pendidikan menengah pertama dan $11,9 \%$ dengan tingkat pendidikan menengah atas. Adapun tingkat pendidikan dapat mempengaruhi sikap ibu hamil dalam mengekspresikan dirinya dalam bersikap positif terhadap senam hamil, walaupun dari uji lanjut tidak terlihat hubungan yang signifikan antara keduanya.
\end{abstract}

Kata Kunci: Senam hamil, Pendidikan, Pengetahuan, Sikap, Ibu hamil trimester III.

\section{ABSTRACT}

In general, women who are pregnant are afraid of facing labor because of pain that can cause fear and anxiety, this can cause physical tension which results in stiff muscles and joints that are not natural, so it is necessary to do pregnancy exercises. Pregnancy exercise is one of the physical exercises in the form of certain movements that support the ease of childbirth and is done specifically to improve the health of pregnant women. This study was conducted to determine the description of knowledge and attitudes of third trimester pregnant women about pregnancy exercise. This study was conducted on 42 samples of third trimester pregnant women in Tanete Health Center, Bulukumba with a sampling technique in the form of accidental sampling, namely sampling based on the fact that respondents happened to appear. Data collection in the form of a questionnaire to determine the knowledge and attitudes of respondents about pregnancy exercise by analyzing the level of education of each respondent. The results showed there was a significant relationship between the level of education with the knowledge of pregnant women towards pregnancy exercise with $p$ value $=0.00$. While the level of education and attitude of pregnant women towards pregnancy exercise there is no relationship $p$ value of 0.824 . Of the 45 pregnant women studied who had good knowledge of pregnancy exercises by $26.2 \%$, namely with a high 
school education level, although the knowledge of pregnancy exercise was also distributed to sufficient knowledge which amounted to $28.6 \%$ with a junior secondary education level and $11,9 \%$ with a high school level. The level of education can affect the attitude of pregnant women in expressing themselves in a positive attitude towards pregnancy exercise, although from further tests there is no significant relationship between the two.

Keywords: Pregnancy exercises, Education, Knowledge, attitudes, third trimester pregnant women.

\section{PENDAHULUAN}

Salah satu intervensi perawatan kesehatan yang dilakukan untuk mengurangi atau menurunkan angka kesakitan dan kematian ibu hamil di Indonesia adalah latihan fisik seperti senam hamil. Senam hamil pada masa ini merupakan salah satu solusi self help yang menunjang proses kehamilan, dan kelahiran, ${ }^{1}$ dan merupakan cara yang mendukung kemudahan dalam persalinan karena senam hamil yang dilakukan secara teratur dan intensif, dapat menjaga kesehatan tubuh dan janin yang dikandung secara optimal. ${ }^{2}$ Beberapa manfaat senam hamil yang penting bagi ibu hamil adalah membantu mengontrol tubuh dan menghilangkan rasa sakit atau nyeri saat kehamilan, memperbaiki sirkulasi darah, menghilangkan sakit pinggang, menguatkan otot-otot panggul, mencegah sembelit dan varises, memudahkan proses persalinan, mengontrol berat badan, membuat ibu lebih tenang, mempersiapkan fisik dan mental dalam menjalani proses kelahiran normal. ${ }^{3}$

Menurut Supriatmaja, dkk. (2011), didalam senam hamil terdapat dua tahapan, yaitu tahapan pendahuluan yang tujuannya adalah melemaskan otot-otot supaya tidak terjadi kekakuan pada otot sebelum memulai senam hamil, dan tahapan inti yang bertujuan untuk membentuk sikap tubuh dan melatih pernapasan ibu. ${ }^{4}$ Dasar pengetahuan ibu hamil tentang senam hamil akan sangat membantu jika melakukan olahraga senama hamil ini. Diharapkan dengan berlatih senam hamil secara teratur kelelahan akan berkurang dan akan membuat semangat menjaga kondisi fisik dan mental bertambah. ${ }^{5,6}$ Selain pengetahuan, sikap seorang ibu hamil terhadap senam hamil merupakan persepsi terhadap gerakan dan perubahan yang terjadi setelah mengikuti senam hamil secara rutin. Oleh karena pengenalan tahapan ini perlu pengetahuan dan sikap yang mumpuni, maka dalam penelitian ini akan diukur pengetahuan dan sikap setiap responden dalam hal ini ibu hamil yang mengikuti senam hamil di Puskesmas Tanete, Kabupaten Bulukumba.

\section{METODOLOGI}

\section{Lokasi dan Jenis Penelitian}

Lokasi penelitian dilakukan di Puskesmas Tanete Kecamatan Bulukumpa Kabupaten Bulukumba dengan desain penelitian yang digunakan adalah metode accidental Sampling, yaitu pengambilan sampel didasarkan pada kenyataan bahwa responden kebetulan muncul.

\section{Populasi dan Sampel}

Populasi penelitian adalah semua ibu hamil yang datang dengan sengaja untuk mengikuti senam hamil di wilayah kerja Puskesmas Tanete Kecamatan Bulukumpa Kabupaten Bulukumba. Sedangkan sampel penelitian adalah populasi yang memenuhi kriteria inklusi dengan jumlah sampel $42 \mathrm{ibu}$ hamil. Kriteria inklusi adalah ibu hamil trimester III yang berpartisipasi dalam kegiatan senam hamil yang dilakukan secara rutin di Puskesmas Tanete dan dengan menandatangani surat persetujuan atas dasar kesukarelaan (informed concent).

\section{Metode Pengumpulan Data}

Metode pengumpulan data dengan menggunakan data primer dimana peneliti melakukan penelitian langsung kepada subjek dengan mencatat identitas responden. Sedangkan alat pengumpulan data yang digunakan adalah wawancara, yaitu untuk 
MEDIKA ALKHAIRAAT : JURNAL PENELITIAN KEDOKTERAN DAN KESEHATAN 1(2): $46-51$

e-ISSN: 2656-7822, p-ISSN: 2657-179X

memperoleh informasi tentang karakteristik dan keadaan umum subyek, misalnya umur, pekerjaan, pendidikan, dan seterusnya dan dilanjutkan dengan pengisian kuesioner yang telah disiapkan untuk pertanyaan yang berhubungan dengan pengetahuan dan sikap responden tentang senam hamil.

Data sekunder diperoleh dari instansi yang terkait dengan penelitian ini, dalam hal ini data responden diambil dan dicatat dari Puskesmas Tanete, kecamatan Bulukumpa, Kabupaten Bulukumba.

\section{Analisis Data}

Data diperoleh dari analisis terhadap variabel penelitian yang dilakukan dengan menggunakan uji analisis univariat dan bivariat. Analisis univariat yang dilakukan pada variabel pendidikan, pengetahuan dan sikap masing-masing responden. Sedangkan analisis bivariat yang dilanjutkan dengan uji Chi-Square $\left(X^{2}\right)$, dilakukan untuk melihat hubungan antara variabel pendidikan terhadap pengetahuan responden tentang senam hamil dan terhadap sikap responden tentang senam hamil.

\section{HASIL DAN PEMBAHASAN \\ HASIL}

Variabel yang dinilai pada penelitian ini adalah pendidikan yang diolah dengan menggunakan SPSS 2.0 dengan distribusi frekuensi tingkat pendidikan responden dimulai dari tidak bersekolah hingga sarjana. Hasil yang diperoleh dari 42 responden yang mengikuti senam hamil di Puskesmas Tanete Kecamatan Bulukumpa Kabupaten Bulukumba adalah tingkat pendidikan yang dominan adalah berada pada tingkat Sekolah Menengah Atas (SMA) sebesar 38.1\%, tingkat Sekolah Menengah Pertama (SMP) sebesar $28.6 \%$, disusul tingkat Sekolah Dasar (SD) sebesar 23.8\%, kemudian responden yang tidak bersekolah sebesar 7.1\%. Tingkat Sarjana (S1) hanya ada $2.4 \%$ persen dari jumlah 42 responden (Tabel 1).
Tabel 1.Distribusi frekuensi berdasarkan pendidikan responden di Puskesmas Tanete Kec.Bulukumpa Kab. Bulukumba

\begin{tabular}{ccc}
\hline Pendidikan & Frekuensi & Persentase $(\%)$ \\
\hline Tidak & 3 & 7.1 \\
sekolah & & \\
SD & 10 & 23.8 \\
SMP & 12 & 28.6 \\
SMA & 16 & 38.1 \\
S1 & 1 & 2.4 \\
\hline Total & 42 & 100.0
\end{tabular}

Sumber: Data Primer yang diolah SPSS 20.0

Hasil distribusi frekuensi pengetahuan responden terhadap senam hamil yang diolah secara SPSS 20.0 dapat dilihat pada tabel 2, terlihat bahwa pengetahuan cukup responden $(65.0 \%)$ lebih mendominasi daripada responden yang berpengetahuan baik (28.5\%) maupun yang berpengetahuan kurang (tidak ada satupun responden dalam kategori ini).

Tabel 2. Distribusi frekuensi berdasarkan pengetahuan responden terhadap senam hamil di Puskesmas Tanete Kec. Bulukumpa Kab. Bulukumba

\begin{tabular}{ccc}
\hline Pengetahuan & Frekuensi & Persentase (\%) \\
\hline Baik & 13 & 28.5 \\
Cukup & 29 & 65.0 \\
Kurang & 0 & 0 \\
\hline Total & 42 & 100.0 \\
\hline
\end{tabular}

Sumber: Data Primer yang diolah SPSS 20.0

Berdasarkan distribusi frekuensi sikap responden terhadap senam hamil menunjukkan sikap positif yaitu sebesar $54.8 \%$ lebih mendominasi atas sikap negatif responden terhadap senam hamil sebesar 45.2\% (Tabel 3). 
Tabel 3. Distribusi frekuensi berdasarkan sikap responden terhadap senam hamil di Puskesmas Tanete Kec. Bulukumpa Kab. Bulukumba

\begin{tabular}{ccc}
\hline Sikap & Frekuensi & Persentase (\%) \\
\hline Negatif & 19 & 45.2 \\
Positif & 23 & 54.8 \\
\hline Total & 42 & 100.0 \\
\hline
\end{tabular}

Sumber: Data Primer yang diolah SPSS 20.0

Hubungan antara variabel pendidikan dan pengetahuan responden terhadap senam hamil setelah dianalisa menggunakan uji Chi-Squre menunjukkan nilai $p=0.00(0.00<0.05$, nilai $\alpha)$ hal ini menunjukkan bahwa terdapat hubungan yang signifikan antara tingkat pendidikan responden terhadap pengetahuan responden tentang senam hamil, yang didominasi oleh tingkat pendidikan SMA yang berpengetahuan baik (26.2\%)) dan cukup $(11.9 \%)$.

Tabel 4 Hubungan antara pendidikan terhadap pengetahuan responden tentang senam hamil di Puskesmas Tanete Kec. Bulukumba Kab. Bulukumba

\begin{tabular}{cccccccc}
\hline \multicolumn{8}{c}{ Pengetahuan Senam Hamil } \\
\cline { 2 - 7 } Pendidikan & \multicolumn{3}{c}{ Baik } & \multicolumn{2}{c}{ Cukup } & \multicolumn{2}{c}{ Kurang Nilai $p$} \\
& N & $\%$ & $\mathrm{~N}$ & $\%$ & \multicolumn{2}{c}{ N $\%$} & \\
\hline Tidak & 0 & 0.0 & 3 & 7.1 & 0 & 0.00 & \\
Sekolah & & & & & & \\
SD & 1 & 2.4 & 9 & 21.4 & 0 & 0.00 & \\
SMP & 0 & 0.0 & 12 & 28.6 & 0 & 0 & 0.00 \\
SMA & 11 & 26.2 & 5 & 11.9 & 0 & 0.00 & \\
S1 & 1 & 2.4 & 0 & 0.0 & 0 & 0.00 & \\
\hline Jumlah & 13 & 31.0 & 29 & 69.0 & 0 & 0.00 & \\
\hline
\end{tabular}

Sedangkan hubungan antara tingkat pendidikan dan sikap responden terhadap senam hamil dapat dilihat pada table 5 yang menunjukkan hampir semua responden mempunyai sikap positif terhadap senam hamil.
Tabel 5 Hubungan antara pendidikan dan sikap responden terhadap senam hamil di Puskesmas Tanete Kec. Bulukumpa Kab. Bulukumba

\begin{tabular}{crrrrl}
\hline \multicolumn{5}{c}{ Sikap Terhadap Senam Hamil } \\
\hline Pendidikan & \multicolumn{3}{c}{ Negatif } & \multicolumn{3}{c}{ Positif } & \multirow{2}{*}{ Nilai $p$} \\
\cline { 2 - 5 } & $\mathrm{N}$ & $\%$ & $\mathrm{~N}$ & $\%$ & \\
\hline Tidak Sekolah & 1 & 2.4 & 2 & 4.8 & \\
SD & 4 & 9. & 6 & 14.3 & \\
& 5 & & & \\
SMP & 5 & 11.9 & 6 & 14.3 & 0,824 \\
SMA & 9 & 21.4 & 8 & 19.0 & \\
S1 & 0 & 0. & 1 & 2.4 & \\
& & 0 & & & \\
\hline Jumlah & 19 & 45.2 & 23 & 54.8 & \\
\hline
\end{tabular}

Sumber: Data Primer yang diolah SPSS 20.0

\section{PEMBAHASAN}

Senam hamil merupakan terapi latihan gerak untuk mempersiapkan ibu hamil, secara fisik atau mental, pada persalinan cepat, aman dan spontan karena senam hamil dapat memperkuat dan mempertahankan elastisitas otot-otot dinding perut, ligamen-ligamen, serta otot dan dasar panggul yang berhubungan dengan proses persalinan. Latihan fisik selama kehamilan yang diramu dalam senam hamil membutuhkan tingkat pemahaman dan pengetahuan yang adekuat, sehingga diharapkan tidak terjadi kesalahan gerakan yang menyebabkan efek negatif pada ibu hamil. Sikap merupakan salah satu sarana untuk memudahkan dan mencapai tujuan. Sikap positif seorang ibu hamil terhadap senam hamil, akan memberikan kemudahan pada ibu hamil memahami tentang senam hamil itu sendiri sehingga dapat memberikan efek positif terhadap gerakan selama melakukan senam. Penelitian ini dilakukan dengan tujuan untuk mengetahui hubungan tingkat pendidikan terhadap pengetahuan dan sikap ibu hamil sebagai responden tentang senam hamil.

Berdasarkan hasil penelitian yang dilakukan terhadap 42 ibu hamil dengan latar 
belakang pendidikan yang berbeda-beda menunjukkan bahwa hubungan antara pendidikan dan pengetahuan ibu hamil tentang senam hamil pada umumnya berkategori baik dan cukup (Tabel 4). Hal ini sejalan dengan tingkat pendidikan ibu hamil yang didominasi oleh tingkat menengah atas (Tabel 1). Menurut Notoatmodjo, (2010) yang mengatakan bahwa faktor-faktor yang mempengaruhi pengetahuan salah satu diantaranya yaitu pendidikan. Biasanya pendidikan berkolerasi erat dengan pengetahuan semakin tinggi pendidikan seseorang semakin tinggi pula pengetahuan yang diperoleh. ${ }^{7}$ Walaupun tingkat pendidikan tertinggi adalah S-1 hanya 1 responden yang terdata, akan tetapi dapat dibuktikan pada hasil penelitian ini, terdapat hubungan yang signifikan antara pendidikan dan pengetahuan ibu hamil tentang senam hamil (Tabel 4).

Begitu pula sikap yang ditunjukkan oleh kebanyakan ibu hamil dalam penelitian ini adalah bersikap positif terhadap senam hamil (Tabel 5). Kemungkinan hal ini terjadi karena tingkat pengetahuan ibu hamil berada pada kategori baik dan cukup seperti yang sudah dijelaskan sebelumnya dan sejalan dengan penelitian terdahulu bahwa pada kisaran pendidikan tingkat pengetahuan dan sikap ibu hamil tentang senam hamil berada pada kategori cukup. ${ }^{8,9}$

Sikap yang ada pada diri seseorang merup akan jalan bagi individu untuk mengekspresika $\mathrm{n}$ nilai yang ada pada dirinya, sehingga dengan cara demikian individu tersebut dapat memperoleh kepuasan dengan cara menunjukkan sikap atau nilai pada dirinya. Dalam hal ini, sikap merupakan suatu sarana dalam mencapai tujuan. Sikap positif seorang ibu hamil terhadap senam hamil, akan memberikan kemudahan pada ibu hamil memahami tentang senam hamil itu sendiri sehingga dapat memberikan efek positif terhadap gerakan selama melakukan senam. ${ }^{10,11}$

Selain pendidikan, tidak menutup kemungkinan faktor-faktor lain dapat mempengaruhi pengetahuan dan sikap ibu hamil terhadap senam hamil. Salah satunya kemungkinan informasi, seperti intervensi penyuluhan dari petugas kesehatan mengenai arti penting senam hamil bagi ibu hamil. Dari hasil penelitian mengenai hubungan pendidikan dan pengetahuan serta sikap ibu hamil trimester III terhadap senam hamil di Wilayah Kerja Puskesmas Tanete Kec. Bulukumpa, Kab. Bulukumba maka dapat diperoleh kesimpulan bahwa terdapatnya hubungan signifikan antara tingkat pendidikan ibu hamil terhadap pengetahuan tentang senam hamil. Hal ini ditunjukkan dengan mayoritas ibu hamil yang mengikuti senam hamil di puskesmas tanete adalah ibu hamil yang mempunyai latar belakang pendidikan yang tinggi, yaitu sekolah menengah atas sebesar 26,2\% dengan berkategori baik, walau pengetahuan senam hamil ini pula terdistribusi pada pengetahuan yang cukup yaitu sebesar $28,6 \%$ dengan tingkat pendidikan menengah pertama dan 11,9\% dengan tingkat pendidikan menengah atas.

Adapun tingkat pendidikan dapat mempengaruhi sikap ibu hamil dalam mengekspresikan dirinya dalam bersikap positif terhadap senam hamil, walaupun dari uji lanjut tidak terlihat hubungan yang signifikan antara keduanya.

\section{DAFTAR PUSTAKA}

1. Rusmita E. 2015. Pengaruh senam hamil yoga terhadap kesiapan ibu hamil menghadapi persalinan di RSIA Limijati Bandung. Jurnal Ilmu Keperawatan, Vol. III, No. 2.

2. Manuaba. 2010. Ilmu Kebidanan, Penyakit Kandungan dan Keluarga Berencana. Jakarta: EGC.

3. Anik Mulyani dan Yetty Sukaryati. (2011). Senam Hamil, Senam Nifas dan Terapi Musik. Jakarta.

4. Supriatmaja, dkk. 2011. Pengaruh senam hamil terhadap kala satu dank ala dua. Denpasar: FKMUI

5. Maryuni A. 2012. Senam hamil, senam nifas dan terapi musik. Jakarta: Trans info. 
6. Puspitasari, Y. R. 2012 Tingkat Pengetahuan Ibu Hamil Tentang Senam Hamil Di Puskesmas Jambu Kulon Kecamatan Ceper Kabupaten Klaten. Karya Tugas Ilmiah.

7. Notoatmodjo, S. 2011 Pendidikan dan perilaku kesehatan. Jakarta: Rineka cipta.

8. Sastroasmoro, S. I. S. 2014 Dasar-Dasar Metode Penelitian Klinis. Edisi Ke - 5. Jakarta: Sagung seto.

9. Karmila. 2015. Gambaran pengetahuan ibu hamil tentang sena hamil. Akbid Tahirah Albaeti, Bulukumba. Karya Tugas Ilmiah.
10. Hani Atu Salamah dkk, 2012. Hubungan pengetahuan dan sikap ibu hamil terhadap senam hamil di puskesmas Banguntapani bantul Yogyakarta.karya Tugas Ilmiah

11. Wahyuni, Sri. 2013. Pengaruh Senam Hamil Terhadap Proses Persalinan Pada Primigravida di RSIA 'Aisyiyah Klaten. Jurnal Vol. 1 no. 1 